\title{
Results of calcanectomy in the surgical management of heel ulceration with osteomyelitis in the high risk patient
}

\author{
Ben Yates \\ From Society of Chiropodists and Podiatrists Annual Conference 2010 \\ Bournemouth, UK. 21-23 October 2010
}

\section{Introduction}

Heel ulceration associated with calcaneal osteomyelitis is a very difficult pathology to treat and often results in below knee amputation. Surgical excision of the infected bone and ulcer via calcanectomy has been shown to reduce amputation and mortality rates. The purpose of the study was to review our experience with this procedure and examine factors that might influence outcome.

\section{Method}

Between 2005 and 2010 sixteen patients underwent partial or complete calcanectomy for chronic heel ulceration associated with osteomyelitis. The case notes were reviewed to determine; outcome, pre-operative size and depth of ulceration, degree and type of bone involvement, cause of neuropathy, peripheral vascular disease, BMI, nutritional status, infective organism based upon bone cultures.

\section{Results}

Eleven of the sixteen patients had diabetes. All had neuropathy. Thirteen of the sixteen wounds healed without the need for below knee amputation at a mean of 8 weeks (range 3-28). Factors that could influence outcome in the three failures included; diabetes, pathological fracture involving the subtalar joint, infective organism. The size of the ulcer, BMI, presence of PVD and nutritional status were not relevant factors.

\section{Conclusion}

Calcanectomy is an effective alternative to below knee amputation for chronic heel ulceration with bone infection.

Published: 20 December 2010

doi:10.1186/1757-1146-3-S1-O28

Cite this article as: Yates: Results of calcanectomy in the surgical management of heel ulceration with osteomyelitis in the high risk patient. Journal of Foot and Ankle Research 2010 3(Suppl 1):O28.
Submit your next manuscript to BioMed Central and take full advantage of:

- Convenient online submission

- Thorough peer review

- No space constraints or color figure charges

- Immediate publication on acceptance

- Inclusion in PubMed, CAS, Scopus and Google Scholar

- Research which is freely available for redistribution
() Biomed Central 